\title{
MODERN APPROACHES TO THE ORGANIZATION OF PHYSICAL EDUCATION IN EDUCATIONAL INSTITUTIONS
}

Jumanov 0.S.

Associate Professor, Physical Education And Sports Professionals Institute Of Retraining And Advanced Training, Uzbekistan

\section{ABSTRACT}

The article provides information on modern approaches to the organization of physical education in educational institutions, the factors determining the impact of exercise in the process of pedagogical research, the state of physical culture in society, indicators and general physical fitness.

KEYWORDS:- Physical education, educational institutions, physical culture in society, general physical fitness.

\section{INTRODUCTION}

identified:

In the process of pedagogical research, the factors determining the impact of exercise are 


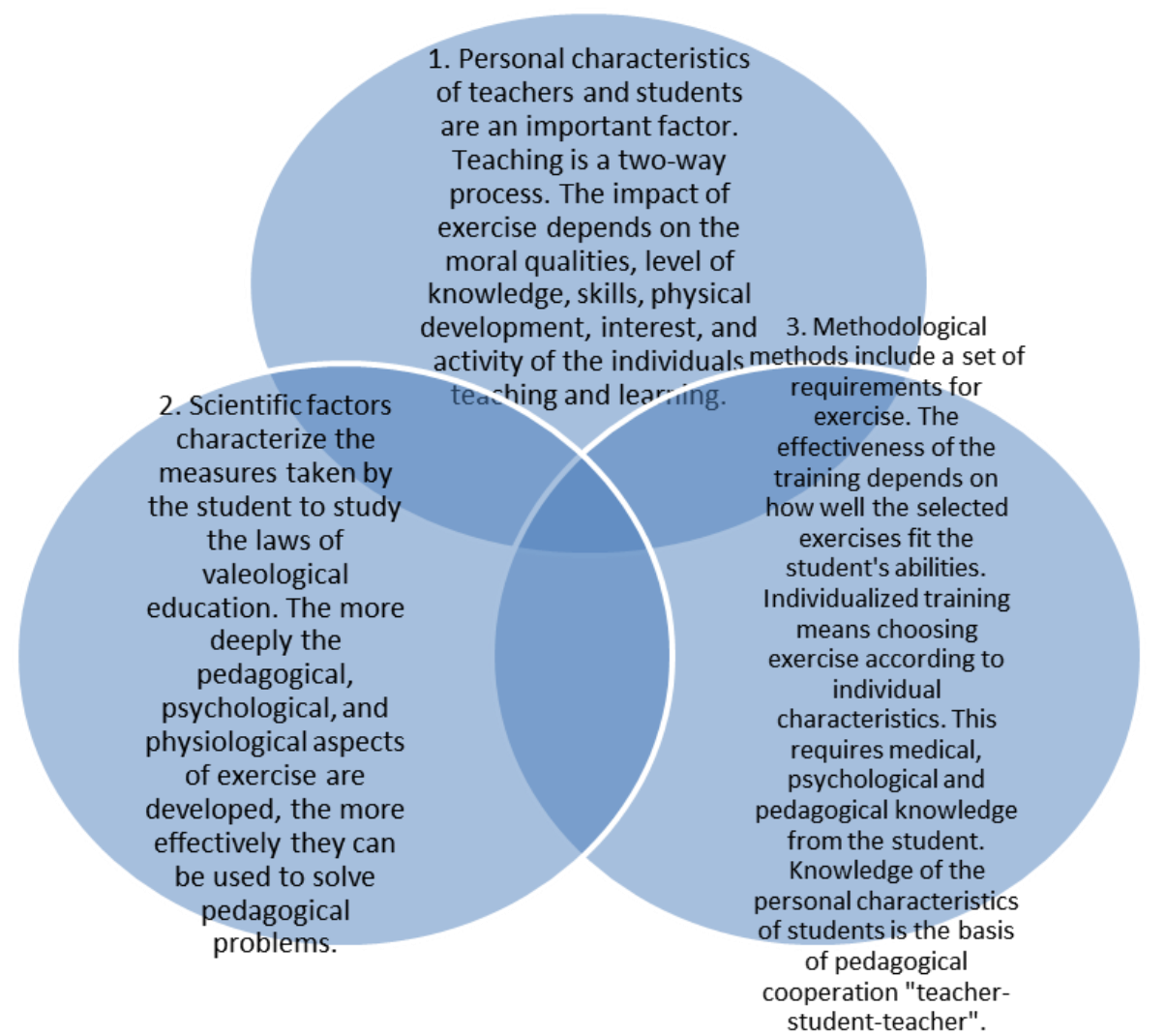

At the same time, identifying students' personal characteristics enhances the impact of physical activity. The individualization of the process of physical development is characterized by the differentiation of training, ways of their passage, norms of physical activity and ways of their management, types of training and methods of pedagogical influence.

The main purpose of mass physical education is to improve health. Let's take a look at how health care is implemented in different countries.

A number of methods have been successfully used in foreign schools to stimulate a stable and, most importantly, conscious interest in physical education since childhood. In many cases, this is the ultimate goal of physical education classes. The main way to achieve this goal is to cultivate an interest in movement activity.

Theoretical training in physical education varies from country to country, but they all have a unique health focus. Healthy Lifestyle Training in the United States and Japan, Healthy Living Team Training in Australia, and Healthy Lifestyle Skills Training in Finland.

In Japan, Healthy Lifestyles start with a large group of kindergarteners. Experts from the Australian Council on Health, Physical Education and Active Recreation consider training in the proper use of leisure time to be one of the most important areas of their work. The Council is actively working to include the above-mentioned subject in the compulsory education program.

In turn, the California Association for Health, Physical Education, Recreation and Dance 
CURRENT RESEARCH JOURNAL OF PEDAGOGICS 2(10): 113-117,

October 2021 DOI: https://doi.org/10.37547/pedagogics-crjp-02-10-22

ISSN 2767-3278

(C)2021 Master Journals

\section{Crossref doi) gr Google}

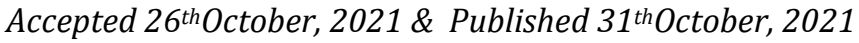

decided to create a health department. The mission of this association is to introduce health school programs in all public schools in California.

These programs help the younger generation develop decision-making skills on how to maintain and improve their health. Classes are planned from kindergarten to 12th grade of secondary schools. It should be noted that such programs are already in place in many US states. Their effectiveness and expediency have been proven in practice. It is a well-known fact that outdoor exercise is an important factor in the physical and mental development of children, students and young people.

Active, national and sports games are not only a means of recreation, but they are also an important unique means of physical as well as mental development.

A variety of physical exercises have a positive effect on the function of various organs, especially the lungs. The most natural way to achieve this goal is to run. Because when you run, most of your muscles move. At the same time, jogging increases the evaporation activity of the skin, as a result of which carbon dioxide and skin waste are eliminated from the body faster, which helps to maintain good health.

Exercise is good for digestion and sleep. Exercise and more outdoors speed up the metabolism, and the excretion of used substances increases the need to eat.

It is also important to note the effect of exercise on a person's mental and physical condition. Physical activity as a means of recreation and leisure creates a calm and pleasant mood, a person feels satisfied with himself, those around him and life. This kind of peace of mind has a positive effect on the physical condition. That is why it is so important to teach young people how to use their free time wisely.
The main tasks in the field of physical culture and health, the development of mass sports and national sports are: daily classes on physical education aimed at the development of children's physical abilities, the normal development of their body, body introduction in preschool institutions.

Introduce a staff of physical education specialists in preschool institutions; to increase the number of compulsory physical education curricula to 46 hours per week. Introduce Olympic education, national games and competitions in the educational process; the introduction of a national week of testing the general physical fitness of pupils and students on special tests, the establishment of three-level badges "Alpomish" and "Barchinoy" in honor of the heroes of the folk epic for successful passing of special tests.

Establishment of a student sports association "Student"; to take measures for the effective use of physical culture and sports in the education of spiritually and physically developed youth in the newly established colleges and lyceums; Organizing the "College Sports" movement, making it a major source of youth involvement in physical education and sports; develop and implement a state program of physical education for women during pregnancy in conjunction with health authorities, the opening of women's sports and fitness clubs everywhere; development of physical culture in the industry through the introduction of physical culture and health measures in the workplace and the organization of mass physical culture and sports in leisure, a healthy lifestyle in the practice of industrial enterprises in order to increase labor efficiency and prolong labor activity of the population as well as the introduction of measures to financially encourage regular physical culture and sports;

Promoting a healthy lifestyle in society, disease prevention, and engaging the general population, 
especially young people, in physical education and sports.

Physical culture, along with the norms of a healthy lifestyle, finds answers to the questions of maintaining and strengthening human health. Physical education, in addition to ensuring physical development, affects almost all human life activities, including mental qualities, selfimprovement, adaptability to society, adaptation to environmental stresses, ensuring a healthy lifestyle, human health throughout life. affects the maintenance and strengthening of the ligament.

\section{The state of physical culture in society is as follows:}

2. The level of comprehensive development of health and physical characteristics;

\section{Level of achievement in sports;}

4. Availability and level of qualification of professional and social physical education

5. The level of use of physical culture in education and upbringing;

\section{Promotion of physical culture and sports;}

7. The level and specificity of the use of the media in the field of physical culture.

Physical culture, together with the norms of a healthy lifestyle, serves to solve practical problems of maintaining and strengthening human health.

At the same time serving physical development, expansion and enhancement of the body's capabilities, physical culture develops the spiritual and moral qualities of the human personality, increases interest in all-round development, increases social activity, helps to correctly perceive various environmental stressors, forms habits of constant adherence to a healthy lifestyle, maintains and strengthens the health of a person throughout his life.

Physical training is a pedagogical process aimed at strengthening health, developing the qualities of movement, improving the overall performance of the body. It is very effective in quickly mastering technical and tactical techniques. Complex sports techniques cannot be successfully mastered in sports without adequate physical training.

Physical training is divided into general auxiliary and special training.

General physical training is the initial stage of an athlete's training. Many exercises used to improve general physical fitness have a wide range of effects on the body. At the same time, each of them is focused on the development of certain qualities. It basically provides the following tasks:

- Comprehensive harmonious development of 
CURRENT RESEARCH JOURNAL OF PEDAGOGICS 2(10): 113-117,

October 2021 DOI: https://doi.org/10.37547/pedagogics-crjp-02-10-22

ISSN 2767-3278

(C)2021 Master Journals

Crossref doi) $\mathrm{g}^{\prime}$ Google

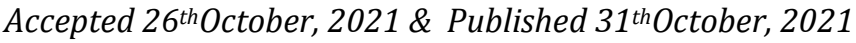

the athlete's body, increase its functional capabilities, development of physical qualities;

- Improving health;

-Proper use of active recreation during intense training competitions.

The effect of exercise on the athlete's body and level of training can be determined using a variety of functional tests.

\section{Trials for additional downloads}

Any functional test (sitting 20 times, running at maximum speed for 15 seconds in one place) can be used to provide additional loads. There is only one requirement for these tests - the amount of downloads must be correct. Extra exercise is usually done before training and 10-20 minutes after training. Response to the test is assessed based on changes in pulsation and blood pressure and recovery.

Special training features. The transition period is a very special part of the system of continuous training. In this case, the main activity will be active recreation. However, this is not a training pause. The training will continue, but its form and content will change significantly.

\section{REFERENCES}

1. The Constitution of the Republic of Uzbekistan.-T. 2019.

2. Law on Physical Culture and Sports (new edition of 1992, 2000, 2015).

3. Popular scientific manual dedicated to the promotion of the Address of the President of the Republic of Uzbekistan Sh.M.Mirziyoev to the Oliy Majlis of the Republic of Uzbekistan among the general public. - Tashkent: 2018 Pages $101-102$.
4. Report of the President of the Republic of Uzbekistan Shavkat Mirziyoyev at the enlarged meeting of the Cabinet of Ministers on the main results of socio-economic development of the country in 2016 and the most important priorities of the economic program for 2017. People's word. //G.201701-16.

5. Kholmirzaev E.J., Nematov B.I., Khojaniyozov B.I. Sports equipment - T., 2010.

6. Konenko I., Malaxov G. Athletic facilities. Profizdat, 1960.

7. Rakhimov MM Fundamentals of the theory and methods of sports training.- T., 2000

8. Ruziev S., Shaternikov E., Baraban I. Uzbekistan Olimpics. -T., 1996.

9. Kudin A.N. Encyclopedia of physical culture and sports. -M., 1982.

10. Catalog of sports equipment and equipment for the establishment of children's sports facilities. -T., Uzbekistan. 2006.

11. Internet; Material from Wikipedia - free encyclopedia.

12. Abdiev A.N, Jumanov O.S., Ne'matov B.I. Sports alphabet.-T., 2008.

13. Kovalyov V.D. Sport games.- M., 1988.

14. Zelenski D. Synchronizing The Mind and Body. FINA coaches seminar, Dallas, Texas 2002. 